\title{
PELATIHAN PEMBUATAN TIANG POT BUNGA PERUM GRIYA SAMPURNA DESA AMPELDENTO KEC. KARANGPLOSO KAB. MALANG
}

\author{
Pondi Udianto $^{1}$, Haris Puspito B ${ }^{2}$, Bagus Wahjudi ${ }^{3}$, Moh. Hartono ${ }^{4}$, RN Akhsanu Takwim ${ }^{5}$ \\ 1,2,3,4,5Jurusan Teknik Mesin, Politeknik Negeri Malang \\ e-mail: ${ }^{1}$ pondi.udianto@polinema.ac.id
}

\begin{abstract}
Abstrak
Perumahan Griya Sampurna merupakan salah perumahan yang ada di Desa Ampeldento Kec. Karangploso Kab. Malang kondisi perumahan dengan penduduk yang heterogen dan merupakan perumahan kelas menengah ke bawah, maka kondisi sarana dan prasarana yang ada perumahan, masih jauh dari layak sebagai sebuah perumahan yang ideal dan nyaman. Salah satu sarana yang masih kurang adalah rambu-rambu lalu lintas

Berkaitan dengan hal tersebut kegiatan pemberdayaan masyarakat telah dilakukan kegiatan yaitu Pelatihan Pembuatan Rambu-rambu Jalan.

Metode yang digunakan dalam kegiatan PKM ini adalah melalui pelatihan teori \& praktek las fabrikasi secara langsung di bengkel warga Perum Griya Sampurna.

Hasil dari kegiatan PKM ini karang taruna dan warga memiliki ketrampilan dasar pengelasan sehingga mampu membuat produk tiang pot bunga.
\end{abstract}

Kata kunci-Pelatihan, ketrampilan, karang taruina, tiang pot bunga

\section{PENDAHULUAN}

P Perumahan Griya Sampurna Anan salah perumahan yang ada di Desa Ampeldento Kec. Karangploso Kab. Malang, merupakan perumahan dengan status Perumahan Sederhana dengan type Rumah 21, 36 dan 45. Dengan luas sekitar 13 hektar, perumahan ini dihuni oleh karyawan swasta, PNS, TNI/Polri dan pegawai di sector formal yang lain.

Penduduk yang heterogen dan merupakan perumahan kelas menengah ke bawah, maka kondisi sarana dan prasarana yang ada perumahan, masih jauh dari layak sebagai sebuah perumahan yang ideal dan nyaman.

Salah satu sarana yang masih kurang adalah kondisi sarana pendukung kenyamanan di setiap jalan atau gang di Perumahan. Kondisi jalan atau gang masih banyak yang gersang karena tidak adanya tanaman atau bunga yang ditamanam di sepanjang jalan.

\section{TINJAUAN PUSTAKA}

\subsection{Proses Pengelasan Busur Listrik}

Pengelasan busur listrik adalah pengelasan dengan memanfaatkan busur listrik yang terjadi antara elektroda dengan benda kerja. Elektroda dipanaskan sampai cair dan diendapkan pada logam yang akan disambung sehingga terbentuk sambungan las. Mula-mula elektroda kontak/bersinggungan dengan logam yang dilas sehingga terjadi aliran arus listrik, kemudian elektroda diangkat sedikit sehingga timbullah busur. Panas pada busur bisa mencapai $5.500 \mathrm{C}^{\circ}$.

Skema las busur bisa dilihat pada gambar 2.3. dibawah ini.

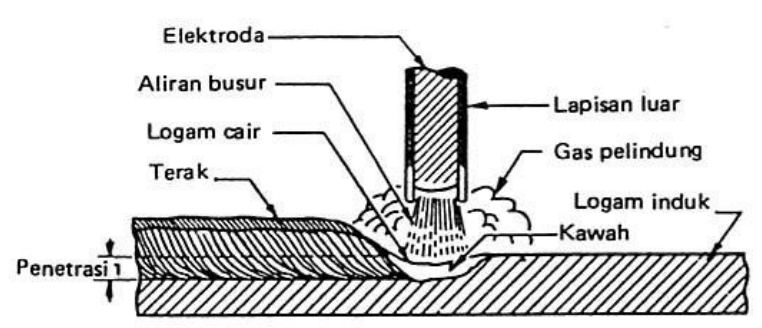

Gambar 2.1. Skema nyala busur. (Sumber TEDC 1982) 


\subsection{Keselamatan pada Proses Pengelasan Las Busur Listrik (SMAW)}

Dalam setiap proses pengelasan, keselamatan adalah aspek yang paling penting, tidak hanya untuk welder, tetapi juga untuk orang- orang lain di sekitarnya. Pengelasan busur listrik (shielded metal arc welding) dapat menyebabkan kecelakaan serius. Akibat-akibat daripada kecelakaan ini:

- luka bakar

- sengatan listrik

- arc flash dan luka bakar (burns)

- Uap/bau pengelasan (fume)

\section{a) Luka bakar}

Luka bakar (burns) adalah kecelakaan yang sangat menyakitkan. Luka bakar ini bisa bersifat ringan: kulit yang kemerahan, atau melepuh atau yang berat yang membutuhkan perawatan serius di rumah sakit, cedera kulit dan jadi cacat seumur hidup.

Dalam pengelasan bususr listrik luka bakar diakibatkan oleh:

- logam panas

- $\operatorname{arc}$

- spatter

Baja berkarbon rendah atau lazim disebut mild steel akan meleleh pada suhu $1535 \quad \mathrm{C}$ yang mana tidak akan ditahan oleh kekuatan kulit manusia. Bahkan sebelum baja itu mulai berubah warnanya dia sudah cukup panas untuk menciptakan luka bakar yang serius.

Apabila arc beroperasi kira-kira $6000 \mathrm{oC}$, maka jelas ini akan dengan mudah membakar pakaian dan kemungkinan bisa mengakibatkan luka bakar yang sangat berat.

Spatter adalah logam yang meleleh yang tercecer oleh karena tenaga yang dikeluarkan oleh arc, dari weld pool. Karena biasanya spatter ini bentuknya kecil saja, maka spatter ini bisa masuk ke kulit melalui lubang pakaian kita, lubang kancing atau pakaian yang kebesaran. Spatter bisa terpelanting keatas mencapai 10 meter dari tempat pengelasan dan bahan yang mudah terbakar bisa dengan cepat dimakan api.

\section{PENCEGAHAN}

Untuk menghindari terjadinya luka bakar maka welder mesti menggunakan pakaian safety seperti :

- Overall panjang dari katun.

- Safety boots

- Sarung tangan kulit untuk welding
- Mantel kulit untuk welding

- Celemek kulit (apron)

- Topi kulit untuk welder

- Leather spats

\section{TINDAKAN PREVENTIF}

ADALAH:

- Selalu berfikir bahwa logam itu panas

- Ketika welding berakhir, dinginkanlah atau diberi tanda dengan kapur bengkel dengan menuliskan "PANAS " sehingga orang lain terhindar dari kecelakaan atau luka.

- Singkirkan atau tutupi bahan-bahan yang mudah terbakar di sekitar tempat kerja anda.

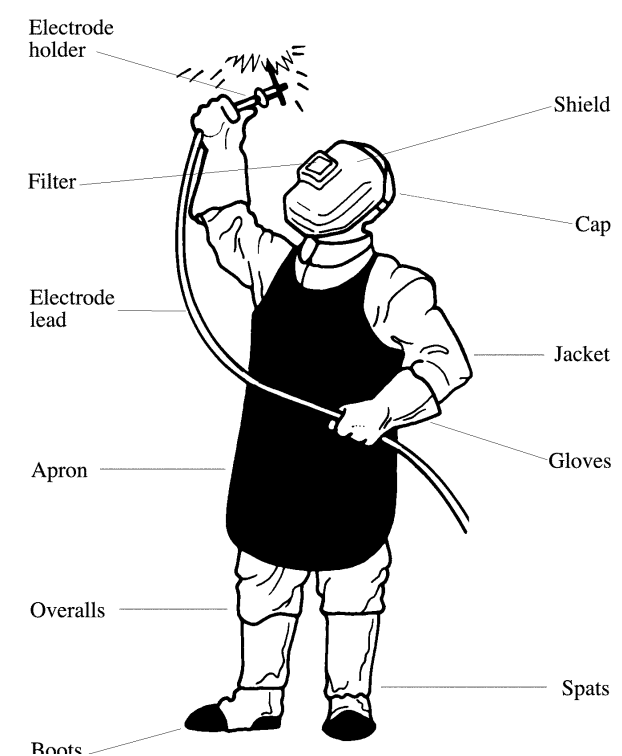

Gambar 2.2. Perlengkapan keselamatan pengelasan busur listrik (SMAW)

Sumber: J.A. OATES 1982

\subsection{Teknik Pengelasan}

Teknik Pengelasan meliputi gerakan pengelasan, posisi pengelasan, dan jenis sambungan.

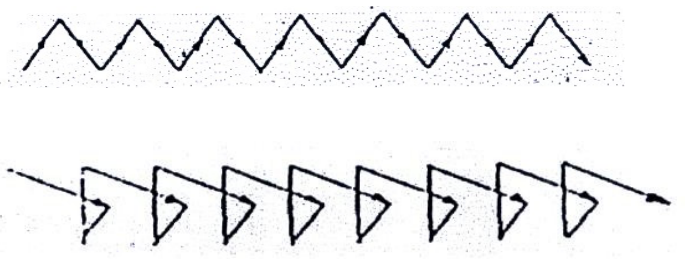

Gambar 2.3. Gerakan pengelasan Zigzag Melingkar dan segitiga 

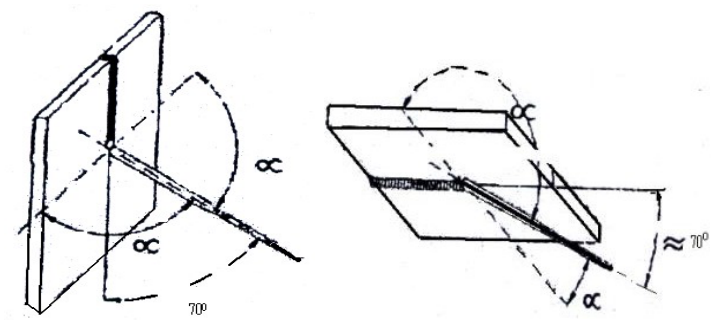

Gambar 2.4. Posisi Pengelasan dibawah tangan, Horisontal, Vertikal Dan diatas kepala
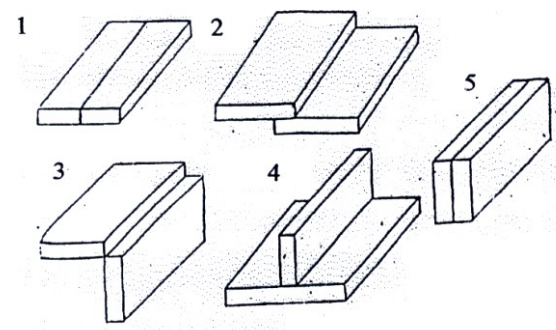

Gambar 2.5. Jenis Sambungan Tumpu, Berimpit, Sudutluar, sambingan T dan sambungan Tepi

\section{METODE PENGABDIAN KEPADA MASYARAKAT}

Metode yang dilakukan dalam kegiatan pembinaan dan pelatihan yang dikemas dalam kegiatan PKM ini antara lain:

1. Awal dari kegiatan PKM antara lain survey lapangan dengan tujuan untuk mempelajari permasalahan yang ada selanjutnya memberikan penawaran tentang pelatihan pengelasan dan pembinaan wirausaha.

2. Kegiatan berikutnya adalah penyusunan proposal kegiatan yang diusulkan kepada unit pelaksana teknik P2M Polteknik Negeri Malang.

3. Selanjutnya setelah mendapat persetujuan maka dilaksanaan kegiatan pelatihan fabrikasi (teori dan praktek) di bengkel las Jurusan Teknik Mesin Politeknik Negeri Malang.

4. Kegiatan akhir dari PKM ini antara lain praktek pembuatan produk tiang pot bunga yang dipasang di lingkungan Perumahan.

\section{HASIL PKM DAN PEMBAHASAN}

\subsection{Hasil}

Kegiatan PKM ini dapat terlaksana dengan baik dan mendapat apresiasi dari warga Perumahan Griya Sampurna khususnya, output dari kegiatan ini tidak hanya berupa ketrampilan dasar fabrikasi (las SMAW) tetapi juga berupa produk yang memberi manfaat bagi warga yaitu rambu-rambu jalan yang sudah terpasang di beberapa titik jalan di lingkungan Perumahan Griya Sampurna.

Pembuatan dan pemasangan tiang pot bunga dipasang di lingkunanr Perumahan Griya Sampurna
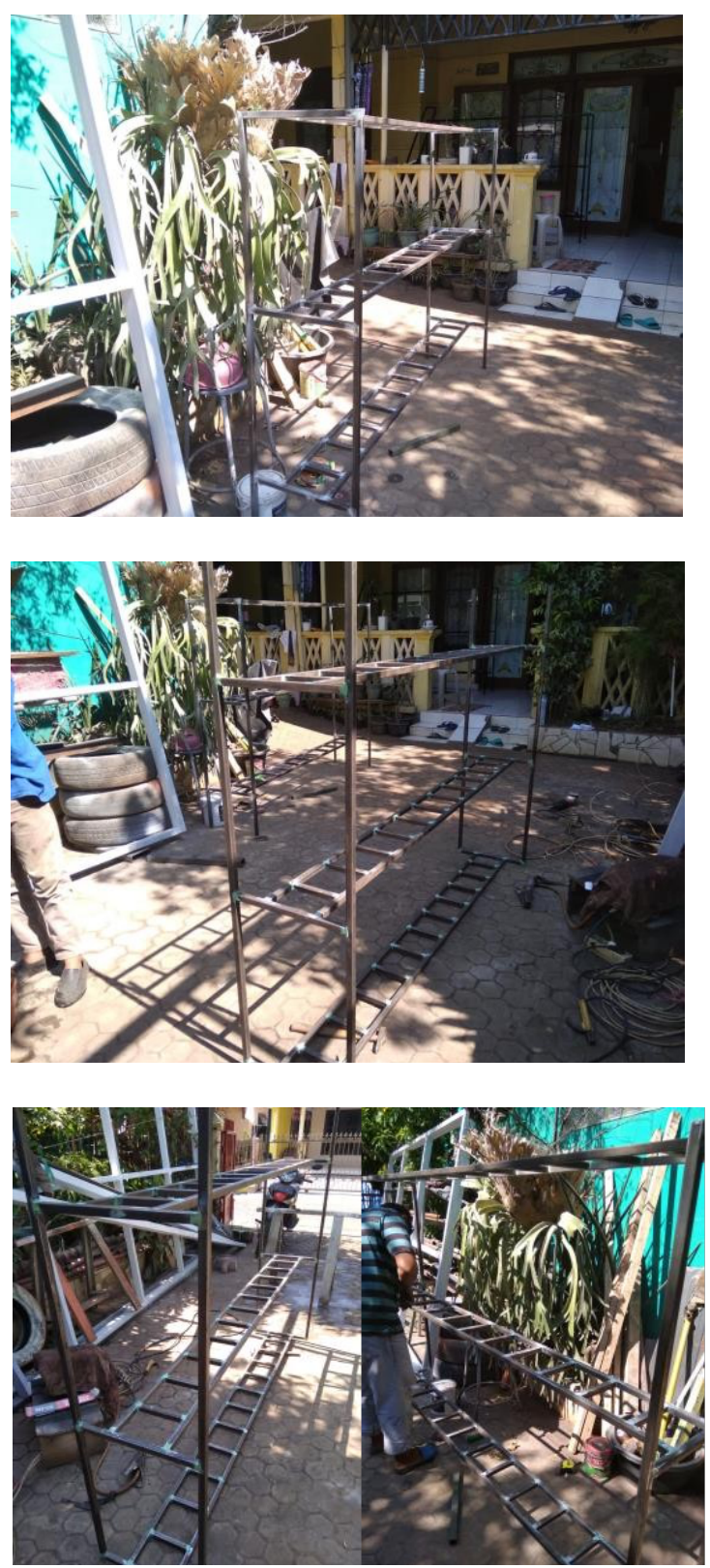

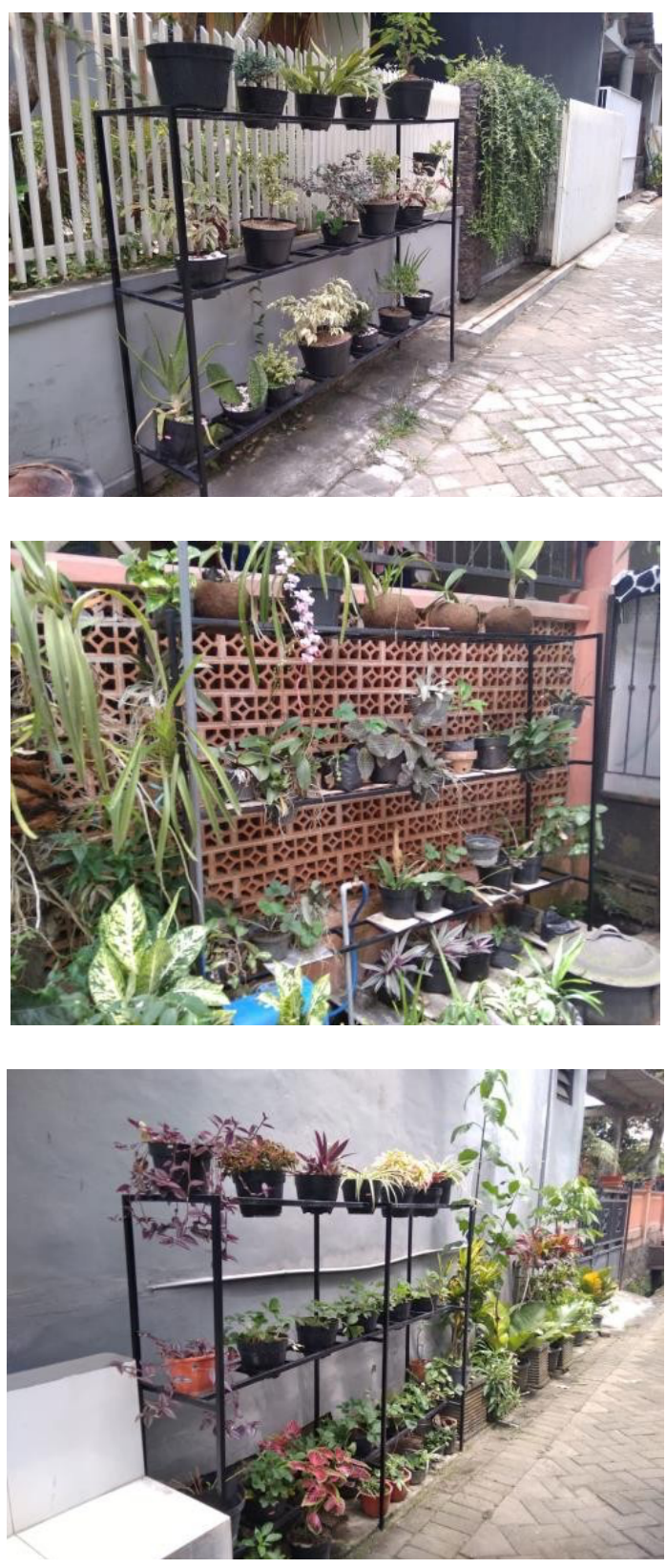

\subsection{Pembahasan}

Melalui kegiatan PKM diketahui bahwa kegiatan ini tidak hanya sebagai suatu wadah kegiatan pengabdian lembaga perguruan tinggi kepada masyarakat tetapi juga sebagai upaya kegiatan menyambung tali silaturahmi antara dunia pendidikan dengan masyarakat. Sehingga melalui kegiatan PKM ini diharapkan peningkatan kualitas SDM tidak hanya dapat ditempuh dari jalur formal tetapi juga dapat ditempuh dari kegiatan seperti PKM ini.

5. KESIMPULAN DAN SARAN

\subsection{Kesimpulan}

PKM mampu memberikan kontribusi yang baik tidak hanya kemampuan soft skill tetapi kemampuan membuat produk sederhana yang memberi manfaat bagi masyarakat.

\subsection{Saran}

Agar lebih bermafaat sebaiknya PKM dibuat terpadu dan berkelanjutan.

\section{DAFTAR PUSTAKA}

1. Fabrikasi logam,Blok Teknik mesin ITS, http://www.teknikmesin.net/2012/10

2. Anonimous, Pengelasan dan Pemotongan, TEDC, Bandung, 1982

3. Musaikan, Ir, Teknik Las, FTI Jurusan Teknik Mesin ITS, Surabaya, 1989 